\title{
Rare dosage abnormalities flanking the SHOX gene
}

\author{
David J. Bunyan ${ }^{1,2^{*} \mathbb{D} \text {, Evelien Gevers }}{ }^{3,4}$, James I. Hobbs ${ }^{1}$, Philippa J. Duncan-Flavell ${ }^{1}$, \\ Rachel J. Howarth ${ }^{1}$, Muriel Holder-Espinasse ${ }^{5}$, Philippe Klee ${ }^{6}$, Roxane Van-Heurk ${ }^{7}$, Laure Lemmens ${ }^{8}$, \\ Maria Teresa Carminho-Rodrigues ${ }^{7}$, Zainaba Mohamed ${ }^{9}$, Aruna Goturu ${ }^{10}$, Claire R. Hughes ${ }^{4}$, \\ Michal Ajzensztejn ${ }^{11}$ and N. Simon Thomas ${ }^{1,2}$
}

\begin{abstract}
Background: Transcriptional regulation of the SHOX gene is highly complex. Much of our understanding has come from the study of copy number changes of conserved non-coding sequences both upstream and downstream of the gene. Downstream deletions have been frequently reported in patients with Leri-Weill dyschondrosteosis or idiopathic short stature. In contrast, there are only four cases in the literature of upstream deletions that remove regulatory elements. Although duplications flanking the SHOX gene have also been reported, their pathogenicity is more difficult to establish. To further evaluate the role of flanking copy number variants in SHOX-related disorders, we describe nine additional patients from a large SHOX diagnostic cohort.

Results: The nine cases presented here include five with duplications (two upstream of SHOX and three downstream), one with a downstream triplication and three with upstream deletions. Two of the deletions remove a single conserved non-coding element (CNE-3) while the third does not remove any known regulatory element but is just $4 \mathrm{~kb}$ upstream of SHOX, and the deleted region may be important in limb bud development. We also describe six families with novel sequence gains flanking SHOX. Three families had increased dosage of a proposed regulatory element approximately $380 \mathrm{~kb}$ downstream of SHOX (X:970,000), including one family with the first ever reported triplication of this region. One family had two in cis downstream duplications co-segregating with LWD, and the two others had a duplication of just the upstream SHOX regulatory element CNE-5.
\end{abstract}

Conclusions: This study further extends our knowledge of the range of variants that may potentially cause SHOXrelated phenotypes and may aid in determining the clinical significance of similar variants.

Keywords: SHOX, Regulatory element, Deletion, Duplication

\section{Background}

Leri-Weill dyschondrosteosis (LWD; MIM ID \# 127300) [1], characterised by mesomelic disproportionate short stature and Madelung deformity of the wrist, is a pseudoautosomal dominantly inherited skeletal dysplasia. Heterozygous deletions or sequence variants resulting in haploinsufficiency for the short-stature

\footnotetext{
*Correspondence: dbunyan@nhs.net

1 Wessex Regional Genetics Laboratory, Salisbury District Hospital,

Salisbury SP2 8BJ, Wiltshire, UK

Full list of author information is available at the end of the article
}

homeobox-containing gene (SHOX;MIM ID \# 312865) are the only known genetic cause of LWD $[2,3]$ and have also been reported in 1.5-15\% of cases of idiopathic short stature (ISS; MIM ID \# 300582), defined as a height below the 3rd centile or two standard deviations below the mean $(-2 \mathrm{SD})$ in the absence of known specific causative disorders [4-8]. Homozygosity or compound heterozygosity for SHOX variants results in Langer mesomelic dysplasia (LMD; MIM ID \# 249700), the most severe end of the spectrum of SHOX-related disorders with significant short stature, limb aplasia, a small ulna and fibula, 
a small mandible plus thickening and curvature of the radius and tibia [2, 3, 9-11].

The characterisation of deletions downstream of SHOX identified putative DNA elements that act as long-range enhancers [12,13]. Parallel comparative genomic studies identified multiple conserved non-coding DNA elements (CNEs) downstream of SHOX, four of which have been demonstrated to have transcriptional activity, namely CNE4 (X:714,085-714,740 (hg19)), CNE5 (X:750,825751,850), CNE7 (ECR1; X:780,700-781,220) and CNE9 (ECS4; X:834,746-835,567) [14-17]. However, regions with regulatory activity are not always highly conserved [18, 19]; therefore, characterising novel copy number variants $(\mathrm{CNVs})$ in individuals with a $S H O X$-related phenotype is important to try and identify further potential regulatory elements. This approach identified a potential additional regulatory element at approximately X:970,000 $[20,21]$. The most recent cis-regulatory element to be identified was ZED (Zeugopodal Enhancer Downstream of $S H O X)$ located at X:827,128-827,691 [19] which was shown to be the critical region within the common downstream $47.5 \mathrm{~kb}$ X:780,550-828,092 deletion [17, 22].

There are three known CNEs upstream of SHOX which have transcriptional activity: CNE-5 (X:398,357398,906), CNE-3 (X:460,279-460,664) and CNE-2 $(516,610-517,229)$ [23]. Deletions upstream of SHOX are infrequently reported compared to downstream deletions with only four previously reported probands with upstream CNEs deletions, all in individuals with ISS [24-26]. Upstream SHOX duplications are also comparatively rare with only four reported to date, all in patients with ISS. One of these duplications involved all three upstream CNEs [27] while two other reported cases involved two of the upstream elements (CNE-5/CNE-3 and CNE-3/CNE-2) [28]. The only patient reported to date with a duplication of a single upstream CNE had a duplication of CNE-2 [29].

It is accepted that SHOX downstream deletions that remove regulatory elements can result in SHOX haploinsufficiency, but other, rarer flanking dosage abnormalities are more difficult to interpret, in part due to their rarity in the literature. In this paper, we describe five individuals with a $S H O X$ upstream dosage abnormality from a large SHOX cohort, including two deletions and two duplications of a single upstream CNE, plus an additional upstream deletion that contains no known CNE but removes part of a region that may be involved in limb bud development. We also present four probands with SHOX downstream dosage abnormalities: three short stature probands with unique $\mathrm{CNV}$ gains containing the proposed $X: 970,000$ regulatory element, including the first reported case of a triplication of this region, and an LWD family with two in cis downstream duplications.

\section{Methods}

\section{Study cohort}

Patients 1-8 were identified from a SHOX cohort of 1963 referrals to the Wessex Regional Genetics Laboratory (WRGL). All patients referred specifically for SHOX analysis were included in the cohort, regardless of the referral reason. The deletions, duplications or triplication identified below were not detected in 22,017 array comparative genome hybridisation $(\mathrm{aCGH})$ referrals to the WRGL (predominantly referred with developmental delay) or two cohorts of anonymised healthy controls totalling over 800 individuals [22, 27]. Patient 9 was identified after referral to the Switzerland Health Service. The probands presented here were consented for SHOX analysis as part of their routine clinical care within the UK National Health Service (Patients 1-8) and the Switzerland Health Service (Patient 9).

Purified genomic DNA obtained from blood samples was extracted according to standard protocols. Analysis of $S H O X$ and its flanking regions was carried out using the following techniques:

\section{SHOX multiplex ligation-dependent probe amplification (MLPA) analysis}

MLPA [30] was performed using the current SHOX kit at the time of testing according to the manufacturer's protocol (P018-G1; MRC-Holland, Amsterdam, The Netherlands). Abnormal MLPA data were repeated on a separate run in order to confirm the results.

\section{Sequencing of the SHOX coding region}

Direct sequencing of all the coding exons (isoform A, NM_000451.3, exons 2 to 6a) was carried out to exclude the presence of single-nucleotide variants and small deletions/insertions in the SHOX coding sequences and intron/exon boundaries (primer sequences available upon request).

\section{aCGH analysis}

The sizes of the SHOX flanking region duplications in the probands 1-4 and 6 were further defined in the Salisbury laboratory using aCGH analysis. The aCGH was performed using Oxford Gene Technologies (OGT, Oxford, UK) 60-mer oligo-array printed in $8 \times 60 \mathrm{~K}$ International Standard Cytogenomic Array (ISCA) Consortium configuration, according to manufacturer's instructions, using Kreatech's pooled control DNA as a reference (Kreatech Diagnostics, Amsterdam, Holland). Slides were scanned using a G2539A Agilent microarray scanner (Agilent Technologies, Wokingham, UK) and analysed using OGT's CytoSure Interpret (v3.6) microarray software. The duplications in Patient 5 and 9 were confirmed and 
sized using single-nucleotide polymorphism array (SNP array) testing in external laboratories.

\section{Long-range PCR}

As Patient 3 had a deletion below the detection limits of aCGH, long-range PCR of the deletion region was carried out in order to define the breakpoints. Essentially, PCR forward primers were designed at approximately $1-\mathrm{kb}$ intervals across the potentially deleted region, and these were used in conjunction with a reverse primer situated immediately downstream of the maximum extent of the deletion as defined by aCGH. One primer pair produced a PCR product that was not present in normal controls, and this was subsequently Sanger sequenced to determine the breakpoints. Long-range PCR was also required for patient 2 , but that involved a single pre-determined primer pair.

All chromosomal location data are based on the Ensembl hg19 assembly. As the SHOX gene lies within the pseudo-autosomal region, the dosage abnormalities may be on the $\mathrm{X}$ or the $\mathrm{Y}$ chromosome in males, but the locations given here refer to the $\mathrm{X}$ chromosome for all individuals to aid comparison.

\section{Results}

All patients underwent SHOX diagnostic testing, comprising sequencing of the SHOX coding exons and MLPA. All variants were initially detected by MLPA and then further defined using aCGH, SNP array testing and Sanger sequencing where applicable. The minimum and maximum breakpoints of the CNVs are shown in Fig. 1 and Table 1. We cannot rule out that the additional material is located elsewhere in the genome, and the exact location and orientation of the triplicated and duplicated segments could not be determined.

Sanger sequencing excluded the presence of a SHOX pathogenic coding sequence variant in all individuals. Although some individuals had additional molecular or biochemical testing, none underwent whole exome sequencing so other potential causes of short stature have not been excluded. The $Z$-score (standard deviation) given for all patient heights is based on the relevant World Health Organisation length-for-age charts.

The clinical information, inheritance patterns and molecular results are summarised in Table 1, and the relevant pedigrees of the four families where samples from additional family members were available are shown in Fig. 2.

\section{Discussion}

Deletions flanking the $S H O X$ gene are an established cause of $S H O X$-related phenotypes. However, CNVs near the $S H O X$ gene should be interpreted with caution as the PAR1 region is highly repetitive and prone to structural rearrangements. The difficulty in distinguishing between a benign $\mathrm{CNV}$ and a clinically relevant $\mathrm{CNV}$ with variable phenotypic expression is demonstrated by the common $47.5 \mathrm{~kb}$ SHOX downstream deletion where six of the 14 probands with the X:780,550-828,092 deletion (43\%) in one cohort had inherited the variant from a phenotypically normal parent [22]. Nevertheless, the study of such cases is important to increase our understanding of SHOX regulation and to try to identify the aetiology of these rearrangements.

We present nine novel CNVs flanking the SHOX gene in probands referred specifically for diagnostic SHOX testing; the frequency was $8 / 1963$ for patients tested in the WRGL SHOX cohort. None of these CNVs were identified in 22,017 patients referred to the WRGL for diagnostic aCGH testing (although only eight of the nine variants are detectable by aCGH), and no comparable deletion or duplication has been reported in the Database of Genomic Variants (http://projects.tcag.ca/variation/) or in over 800 anonymised healthy controls analysed by MLPA [22, 27]. While it is not possible to unequivocally demonstrate causality, the identification of rare novel

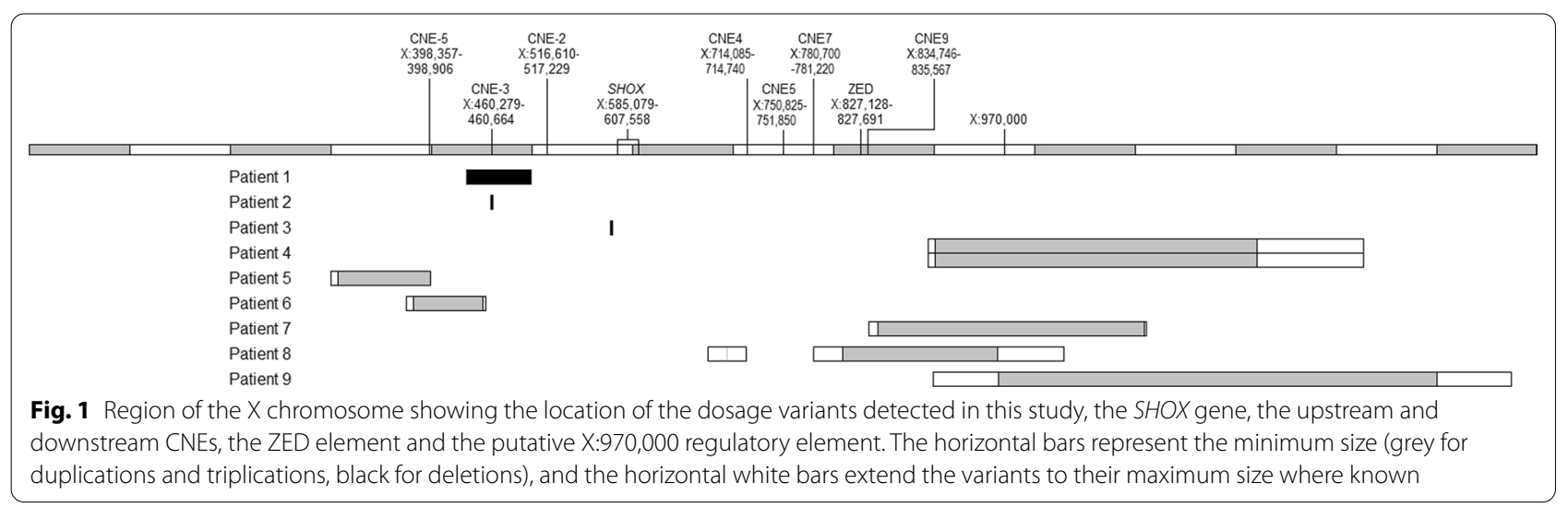




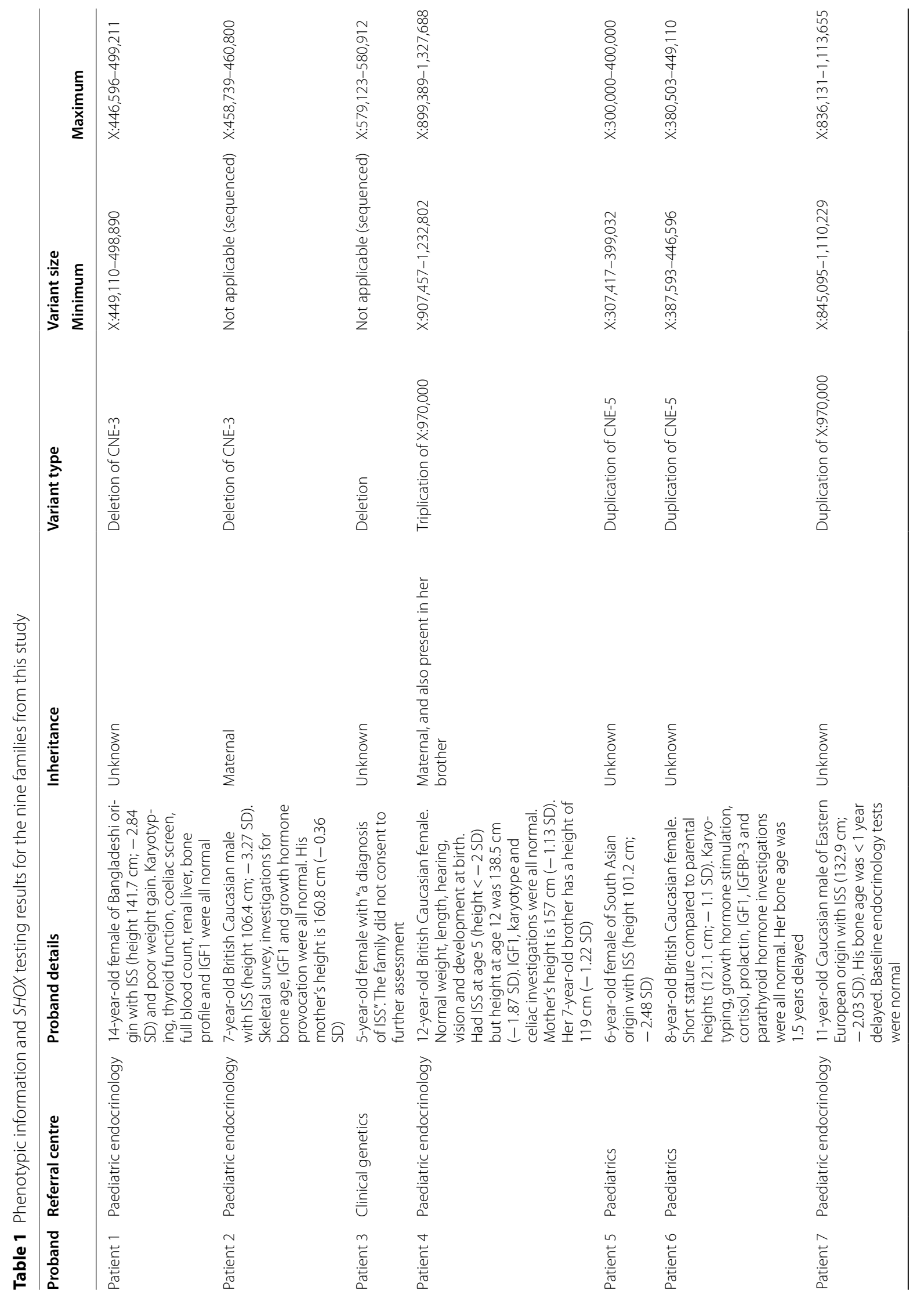




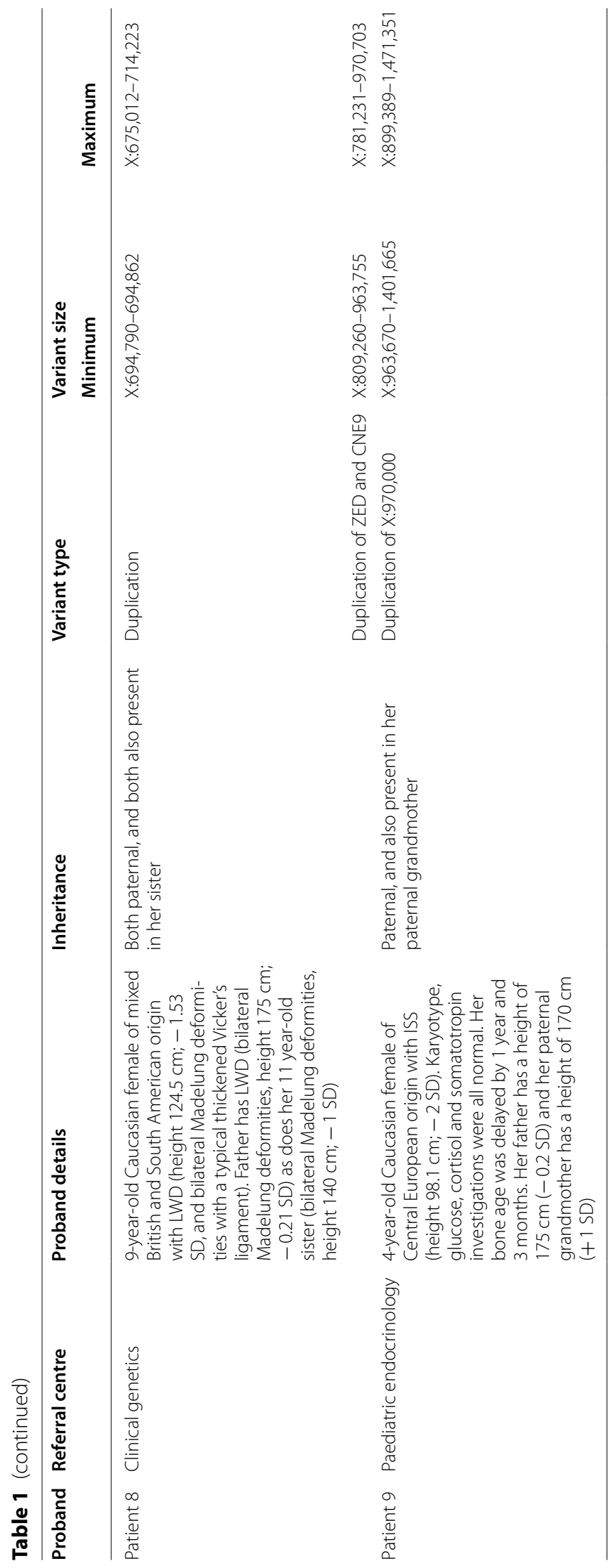




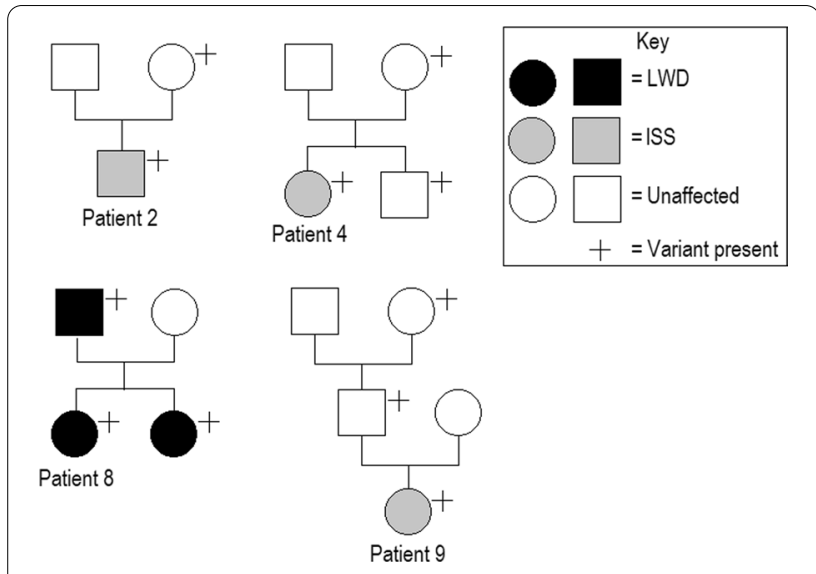

Fig. 2 Pedigrees and inheritance patterns of the four families where samples from additional family members were available

CNVs provides evidence for the importance of this class of abnormality and may help to define critical regulatory regions.

In this study, we describe three patients with small deletions upstream of SHOX, all in individuals with ISS. All of the four previously reported upstream deletions were also seen in patients with ISS [24-26]; therefore, upstream deletions may be associated with a more subtle phenotype than downstream deletions which can often result in LWD. The deletions in Patients 1 and 2 remove part or all of CNE-3. All four previously reported upstream deletions involved the loss of CNE3, plus CNE-2 and/or CNE-5 [24-26]. Therefore, CNE-3 appears to be the critical upstream element with the loss of CNE-3 sufficient to cause ISS.

In contrast, the deletion in Patient 3 does not contain any known regulatory elements. However, the deleted interval contains a segment strongly conserved down to zebrafish, and a predicted layered H3K27Ac mark, often found near active regulatory elements or chromatin loops [31], is located close to the deletion. Figure 3 shows the UCSC genome browser output (http://genome-euro. ucsc.edu) from CNE-5 to X:970,000 including sequence conservation and predicted layered H3K27Ac marks. The layered H3K27Ac mark approximately $10 \mathrm{~kb}$ upstream of the deletion in Patient 3 does not correspond to any known regulatory element. Enriched H3K27 acetylated regions in developing human limbs [31] are shown in greater detail in the lower half of Fig. 3. The deleted region removes part of region that is acetylated at three of the four developmental stages for which data are available (E33, E41, E44 and E47 datasets) [31]. Therefore, the deleted interval may be essential for normal SHOX expression.

The two duplications in Patient 8 segregate with LWD in the proband and two other affected family members. In contrast, assignation of causality for the duplications in Patients 4-7 and 9 is more difficult; they were

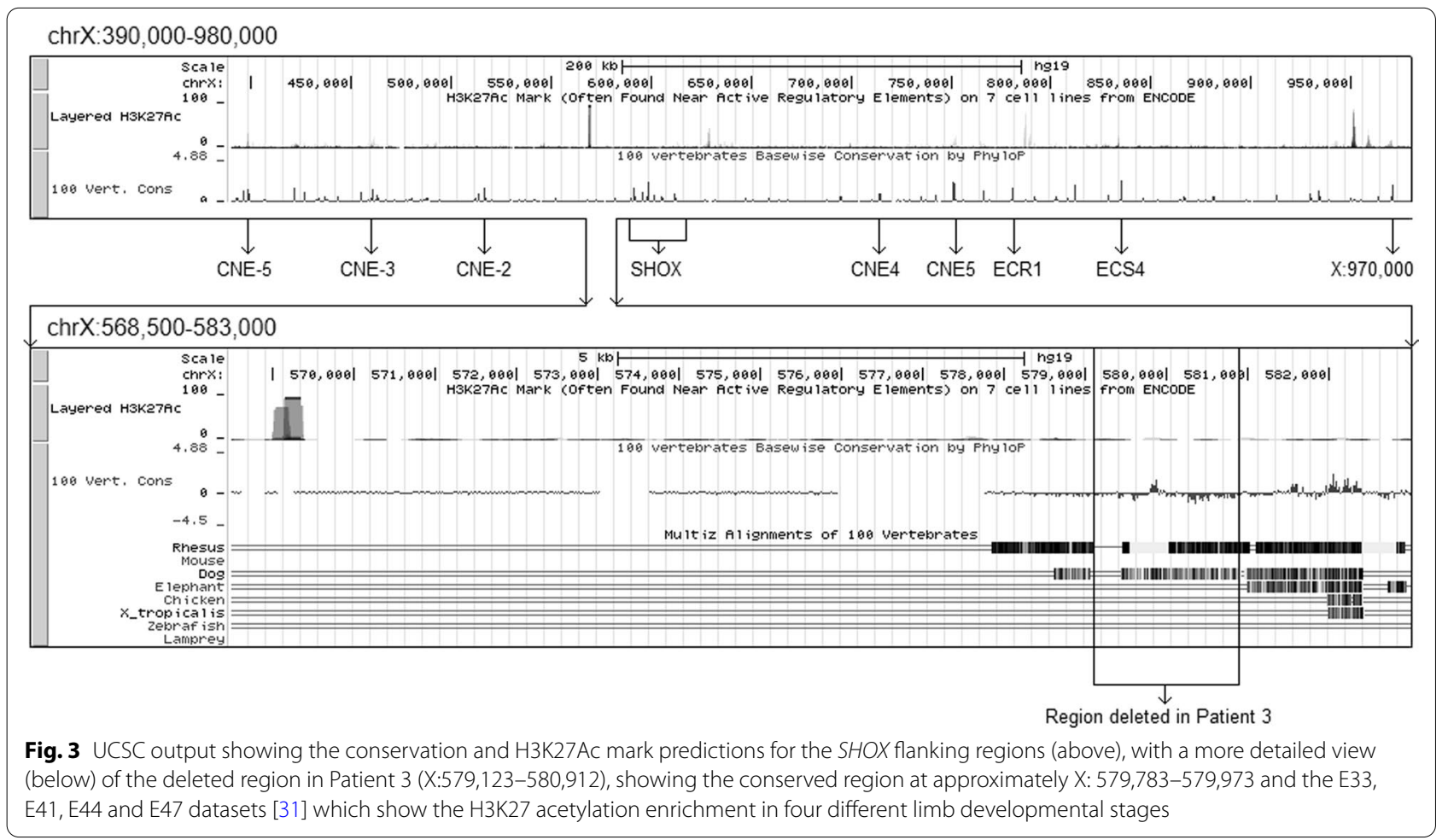


ascertained through their short stature which is a common phenotype with multiple causes. Since flanking CNVs are generally associated with mild SHOX-related phenotypes, they could result in reduced expression rather than complete haploinsufficiency. Within SHOX cohorts, duplications of upstream CNEs have previously been reported exclusively in individuals with ISS $[25,28]$, although a duplication of all three upstream CNEs has been reported in one control individual from a study of the SHOX region [29] and one individual from a study of genome-wide CNVs [32]. Similarly, duplication of the proposed X:970,000 regulatory element [20] has also been reported as a copy number variant in another large study [33]. However, as the common $47.5 \mathrm{~kb}$ downstream deletion $[17,22]$ is associated with a highly variable phenotypic effect ranging from normal to Leri-Weill dyschondrosteosis (with $43 \%$ of carrier parents being phenotypically normal [22]), the presence of a SHOX flanking variant in a phenotypically normal individual does not preclude that variant from being causative but with a variable phenotype. SHOX phenotypic variability may also be influenced by modifier genes such as CYP26C1 [34].

In contrast with deletions, the causative mechanism(s) for duplications is less clear as there is no loss of sequence material. However, there is evidence to suggest that the duplication of only the downstream CNE9 regulatory element is sufficient to cause ISS $[18,28,29]$. There are a number of potential explanations that can be considered. Firstly, gene regulation depends not only on the presence of regulatory elements and associated complexes but also on the nuclear positioning, chromatin conformation and integrity of the flanking chromosomal segments [35, 36]. Insertion of duplicated material between SHOX and a given CNE would alter the normal chromatin structure and potentially affect gene expression. Similarly, the CNVs in patients 3, 4, 7 and 9 contain, or are close to, a predicted active H3K27Ac mark and could disrupt normal chromatin loop formation that links enhancers and promotors [37, 38].

Secondly, the presence of additional copies of a regulatory element may act to reduce the availability of transcription factors that bind to these elements. For example, as three copies of the X:970,000 region exist on one chromosome in Patient 4, transcription factors that bind to this region will only bind in the "optimal place" one third of the time. A similar mechanism could be postulated for Patients 5, 7 and 9.

Thirdly, although approximately $95 \%$ of large duplications genome-wide are reported to be tandem [39], there could be undetected complexity, particularly in Patient 8 who has two in cis downstream duplications. An inverted tandem duplication may allow single-stranded DNA to form a quasipalindromic loop which could block any enhancers contained within the region.

Fourthly, downstream duplications could disrupt the adjacent topologically associated chromatin domain (TAD) boundary. TADs are discrete compartments of approximately $1 \mathrm{Mb}$ in size, which restrict regulatory chromosomal interactions $[38,40]$. TAD boundary regions contain insulators that block interactions across adjacent TADs [41] and variants that disrupt TAD structures can cause malformation syndromes through de novo enhancer-promoter interactions and mis-expression [40]. The SHOX 3' TAD boundary has been mapped immediately upstream of the CRLF2 gene (i.e. close to $\mathrm{X}: 1,314,890)$ [38], although other publications describe the SHOX TAD as covering an approximate region of either X:284,600-1,355,600 [25] or X:350,001-1,035,000 [37]. The duplication in Patient 9, and possibly the triplication in Patient 4, spans the SHOX TAD and would create an extra copy of the TAD boundary. In addition, the duplications seen in Patients 7 and 8 are contained within the SHOX TAD, so they would move the TAD boundary further from SHOX which may alter essential 3-D genomic architecture.

\section{Conclusions}

Although the dosage abnormalities presented here were all formally classified and reported as variants of uncertain clinical significance, they are rare or absent in control populations. The results from Patient 3 suggest an additional SHOX critical region near X:581,000, and the deletions in Patients 1 and 2 provide further evidence that the loss of CNE-3 can cause ISS. Also, the triplication seen in Patient 4 and the two novel duplications in Patients 7 and 9 involving the $\mathrm{X}: 970,000$ region provide further evidence that copy number gains containing X:970,000 may be a cause of short stature. Therefore, this study further extends our knowledge of the range of variants that may potentially cause $S H O X$-related phenotypes.

\section{Abbreviations \\ aCGH: Array comparative genome hybridisation; CNEs: Conserved non-coding DNA elements; CNVs: Copy number variants; ISS: Idiopathic short stature; LWD: Leri-Weill dyschondrosteosis; MLPA: Multiplex ligation-dependent probe amplification; PAR1: Pseudoautosomal region 1; SNP array: Single-nucleotide polymorphism array; WRGL: Wessex Regional Genetics Laboratory.}

\section{Acknowledgements}

We are grateful to all patients and clinicians who were involved in our SHOX cohort, and to the molecular cytogeneticists who assisted with the ACGH data.

\section{Authors' contributions}

DJB and NST took part in conceptualisation; DJB, JIH, PJDF, RJH, LL, NST involved in validation; DJB, EG, JIH, PJDF, RJH, MHE, PK, RVH, LL, MTCR, ZM, AG, $\mathrm{CRH}, \mathrm{MA}$ took part in investigation; EG, MHE, PK, RVH, MTCR, ZM, AG, CRH, MA involved in resources; DJB and NST involved in writing —original draft; DJB and 
NST participated in writing-review \& editing; NST took part in supervision. All authors read and approved the manuscript.

\section{Funding}

No funds, grants or other support was received.

\section{Availability of data and materials}

The datasets generated during and/or analysed during the current study are available from the corresponding author on reasonable request.

\section{Declarations}

\section{Ethics approval and consent to participate}

The study was performed in accordance with the ethical standards as laid down in the 1964 Declaration of Helsinki. The probands presented here were consented for SHOX analysis as part of their routine clinical care within the UK National Health Service (Patients 1-8) and the Switzerland National Health Service (Patient 9), so research ethics committee approval is not applicable for this study according to the NHS Health Research Authority guidelines (hra.nhs. uk). Written informed consent was obtained from a parent or legal guardian of any participants under 16 years old prior to sample collection.

\section{Consent for publication}

Not applicable.

\section{Competing interests}

The authors have no relevant financial or non-financial interests to disclose.

\begin{abstract}
Author details
${ }^{1}$ Wessex Regional Genetics Laboratory, Salisbury District Hospital, Salisbury SP2 8BJ, Wiltshire, UK. ${ }^{2}$ School of Medicine, University of Southampton, Southampton SO16 6YD, Hampshire, UK. ${ }^{3}$ William Harvey Research Institute, Barts and the London School of Medicine and Dentistry, Queen Mary University of London, Charterhouse Square, London EC1M 6BQ, UK. ${ }^{4}$ Department of Paediatric Endocrinology, Royal London Children's Hospital, Whitechapel Road, Whitechapel, London E1 1BB, UK. ${ }^{5}$ Department of Clinical Genetics, Guy's Hospital, Borough Wing, 7th Floor, London SE1 9RT, UK. ${ }^{6}$ Paediatric Endocrine and Diabetes Unit, Department of Pediatrics, Gynecology and Obstetrics, University Hospitals of Geneva, Geneva, Switzerland. ${ }^{7}$ Department of Medical Genetics, University Hospitals of Geneva, Geneva, Switzerland. ${ }^{8}$ Laboratoire de Diagnostic Moléculaire et Génomique, University Hospitals of Geneva, Geneva, Switzerland. ${ }^{9}$ Department of Paediatric Endocrinology and Diabetes, Birmingham Childrens' Hospital, Steelhouse Lane, Birmingham B4 6NH, West Midlands, UK. ${ }^{10}$ Children's and Adolescent Services, Frimley Park Hospital, Portsmouth Road, Camberley GU16 7UJ, Surrey, UK. ${ }^{11}$ Department of Paediatric Endocrinology, Evelina London Children's Hospital, St Thomas's Hospital, Westminster Bridge Road, London SE1 7EH, UK.
\end{abstract}

Received: 1 June 2021 Accepted: 10 September 2021 Published online: 10 December 2021

\section{References}

1. Leri A, Weill J (1929) Une affection congenitale et symetrique du developpement osseux: la dyschondrosteose. Bull Mem Soc Med Hop (Paris) 53:1491

2. Belin V, Cusin V, Viot G, Girlich D, Toutain A, Moncla A, Vekemans M, Le Merrer M, Munnich A, Cormier-Daire V (1998) SHOX mutations in dyschondrosteosis (Leri-Weill syndrome). Nat Genet 19:67-69. https://doi. org/10.1038/ng0198-67

3. Shears DJ, Vassal HJ, Goodman FR, Palmer RW, Readorn W, Superti-Furga A, Scambler PJ, Winter RM (1998) Mutation and deletion of the pseudoautosomal gene SHOX cause Léri-Weill dyschondrosteosis. Nat Genet 19:70-73. https://doi.org/10.1038/ng0198-70

4. Binder G, Ranke MB, Martin DD (2003) Auxology is a valuable instrument for the clinical diagnosis of SHOX haploinsufficiency in schoolage children with unexplained short stature. J Clin Endocrinol Metab 88(10):4891-4896. https://doi.org/10.1210/jc.2003-030136
5. Stuppia L, Calabrese G, Gatta V, Pintor S, Morizio E, Fantasia D, Guanciali F, Rinaldi M, Scarano G, Concolino D, Giannotti A, Petreschi F, Anzellotti M, Pomilio M, Chiarelli F, Tumini S, Palka G (2003) SHOX mutations detected by FISH and direct sequencing in patients with short stature. J Med Genet 40(2):e11. https://doi.org/10.1136/jmg.40.2.e11

6. Huber C, Rosilio M, Munnich A, Cormier-Daire V (2006) High incidence of SHOX anomalies in individuals with short stature. J Med Genet 43:735-739. https://doi.org/10.1136/jmg.2006.040998

7. Jorge AA, Souza SC, Nishi MY, Billerbeck AE, Libório DC, Kim CA, Arnhold IJ, Mendonca BB (2007) SHOX mutations in idiopathic short stature and Leri-Weill dyschondrosteosis: frequency and phenotypic variability. Clin Endocrinol (Oxf) 66:130-135. https://doi.org/10.1111/j.1365-2265.2006. 02698.x

8. Rappold G, Blum WF, Shavrikova EP, Crowe BJ, Roeth R, Quigley CA, Ross $J$, Niesler B (2007) Genotypes and phenotypes in children with short stature: clinical indicators of SHOX haploinsufficiency. J Med Genet 44:306-313. https://doi.org/10.1136/jmg.2006.046581

9. Langer LO Jr (1965) Dyschondrosteosis, a hereditable bone dysplasia with characteristic roentgenographic features. AJR Am J Roentgenol 95:178-188. https://doi.org/10.2214/ajr.95.1.178

10. Shears DJ, Guillen-Navarro E, Sempere-Miralles M, Domingo-Jimenez R, Scambler PJ, Winter RM (2002) Pseudodominant inheritance of Langer mesomelic dysplasia caused by a SHOX homeobox missense mutation. Am J Med Genet 110:153-157. https://doi.org/10.1002/ajmg.10421

11. Zinn AR, Wei F, Zhang L, Elder FF, Scott Cl Jr, Marttila P, Ross JL (2002) Complete SHOX deficiency causes Langer mesomelic dysplasia. Am J Med Genet 110:158-163. https://doi.org/10.1002/ajmg.10422

12. Benito-Sanz S, Thomas NS, Huber C, Gorbenko del Blanco D, Aza-Carmona D, Crolla JA, Maloney V, Argente J, Campos-Barros A, Cormier-Daire $\checkmark$, Heath KE (2005) A novel class of pseudoautosomal region 1 deletions downstream of SHOX is associated with Leri-Weill dyschondrosteosis. Am J Hum Genet 77:533-544. https://doi.org/10.1086/449313

13. Bertorelli R, Capone L, Ambrosetti F, Garavelli L, Varriale L, Mazza V, Stanghellini I, Percesepe A, Forabosco A (2007) The homozygous deletion of the 3' enhancer of the SHOX gene causes Langer mesomelic dysplasia. Clin Genet 72(5):490-491. https://doi.org/10.1111/j.1399-0004.2007. 00875.x

14. Fukami M, Kato F, Tajima T, Yokoya S, Ogata T (2006) Transactivation function of an approximately 800-bp evolutionarily conserved sequence at the SHOX 3'region: implication for the downstream enhancer. Am J Hum Genet 78:167-170. https://doi.org/10.1086/499254

15. Sabherwal N, Bangs F, Röth R, Weiss B, Jantz K, Tiecke E, Hinkel GK, Spaich C, Hauffa BP, van der Kamp H, Kapeller J, Tickle C, Rappold G (2007) Long-range conserved non-coding SHOX sequences regulate expression in developing chicken limb and are associated with short stature phenotypes in human patients. Hum Mol Genet 16:210-222. https://doi.org/10. 1093/hmg/ddl470

16. Chen J, Wildhardt G, Zhong Z, Röth R, Weiss B, Steinberger D, Decker J, Blum WF, Rappold G (2009) Enhancer deletions of the SHOX gene as a frequent cause of short stature: the essential role of a $250 \mathrm{~kb}$ downstream regulatory domain. J Med Genet 46:834-839. https://doi.org/10.1136/ jmg.2009.067785

17. Benito-Sanz S, Royo JL, Barroso E, Paumard-Hernandez B, Barreda-Bonis AC, Liu P, Gracia R, Lupski JR, Campos-Barros A, Gomez-Skarmeta JL, Heath KE (2012) Identification of the first recurrent PAR1 deletion in LériWeill dyschondrosteosis and idiopathic short stature reveals the presence of a novel SHOX enhancer. J Med Genet 49:442-450. https://doi.org/10. 1136/jmedgenet-2011-100678

18. Fukami M, Naiki Y, Muroya K, Hamajima T, Soneda S, Horikawa R, Jinno T, Katsumi M, Nakamura A, Asakura Y, Adachi M, Ogata T, Kanzaki S, SHOX The Japanese study group (2015) Rare pseudoautosomal copy-number variations involving SHOX and/or its flanking regions in individuals with and without short stature. J Hum Genet 60:553-556. https://doi.org/10. 1038/jhg.2015.53

19. Skuplik I, Benito-Sanz S, Rosin JM, Bobick BE, Heath KE, Cobb J (2018) Identification of a limb enhancer that is removed by pathogenic deletions downstream of the SHOX gene. Sci Rep 8:14292. https://doi.org/10. 1038/s41598-018-32565-1

20. Bunyan DJ, Taylor E-J, Maloney VK, Blyth M (2014) Homozygosity for a novel deletion downstream of the SHOX gene provides evidence for an additional long range regulatory region with a mild phenotypic effect. 
Am J Med Genet Part A 164(11):2764-2768. https://doi.org/10.1002/ ajmg.a. 36724

21. Tsuchiya T, Shibata M, Numabe H, Jinno T, Nakabayashi K, Nishimura G, Nagai T, Ogata T, Fukami M (2014) Compound heterozygous deletions in pseudoautosomal region 1 in an infant with mild manifestations of Langer mesomelic dysplasia. Am J Med Genet 164A:505-510. https://doi. org/10.1002/ajmg.a.36284

22. Bunyan DJ, Baker KR, Harvey JF, Thomas NS (2013) Diagnostic screening identifies a wide range of mutations involving the SHOX gene, including a common $47.5 \mathrm{~kb}$ deletion $160 \mathrm{~kb}$ downstream with a variable effect on gene function. Am J Med Genet Part A 161A:1329-1338. https://doi.org/ 10.1002/ajmg.a.35919

23. Durand C, Bangs F, Signolet J, Decker E, Tickle C, Rappold G (2010) Enhancer elements upstream of the SHOX gene are active in the developing limb. Eur J Hum Genet 18:527-532. https://doi.org/10.1038/ejhg. 2009.216

24. Benito-Sanz S, Aza-Carmona M, Rodríguez-Estevez A, Rica-Etxebarria I, Gracia R, Campos-Barros A, Heath KE (2012) Identification of the first PAR1 deletion encompassing upstream SHOX enhancers in a family with idiopathic short stature. Eur J Hum Genet 20(1):125-127. https://doi.org/10. 1038/ejhg.2011.210

25. Verdin H, Fernández-Miñán A, Benito-Sanz S, Janssens S, Callewaert B, De Waele K, De Schepper J, François I, Menten B, Heath KE, Gómez-Skarmeta $J \mathrm{~L}$, De Baere E (2015) Profiling of conserved non-coding elements upstream of SHOX and functional characterisation of the SHOX cisregulatory landscape. Sci Rep 3(5):17667. https://doi.org/10.1038/srep1 7667

26. Shima H, Tanaka T, Kamimaki T, Dateki S, Muroya K, Horikawa R, Kanno J, Adachi M, Naiki Y, Tanaka H, Mabe H, Yagasaki H, Kure S, Matsubara Y, Tajima T, Kashimada K, Ishii T, Asakura Y, Fujiwara I, Soneda S, Nagasaki K, Hamajima T, Kanzaki S, Jinno T, Ogata T, Fukami M, SHOX The Japanese study group (2016) Systematic molecular analyses of SHOX in Japanese patients with idiopathic short stature and Leri-Weill dyschondrosteosis. J Hum Genet 61:585-591. https://doi.org/10.1038/jhg.2016.18

27. Benito-Sanz S, Barroso E, Heine-Suñer D, Hisado-Oliva A, Romanelli V, Rosell J, Aragones A, Caimari M, Argente J, Ross JL, Zinn AR, Gracia R, Lapunzina P, Campos-Barros A, Heath KE (2011) Clinical and molecular evaluation of SHOX/PAR1 duplications in Leri-Weill dyschondrosteosis (LWD) and idiopathic short stature (ISS). J Clin Endocrinol Metab 96(2):E404-E412. https://doi.org/10.1210/jc.2010-1689

28. Bunyan DJ, Baffico M, Capone L, Vannelli S, lughetti L, Schmitt S, Taylor E-J, Brown SB, Herridge AA, Predieri B, Shears D, Forabosco A, Coviello DA (2016) Duplications upstream and downstream of SHOX identified as novel causes of Leri-Weill dyschondrosteosis or idiopathic short stature. Am J Med Genet Part A 170(4):949-957. https://doi.org/10.1002/ajmg.a. 37524

29. Hirschfeldova K, Solc R (2017) Comparison of SHOX and associated elements duplications distribution between patients (Leiri-Weill dyschondrosteosis/idiopathic short stature) and population sample. Gene 627:164-168. https://doi.org/10.1016/j.gene.2017.06.034

30. Schouten JP, McElgunn CJ, Waaijer R, Zwijnenburg D, Diepvens F, Pals G (2002) Relative quantification of 40 nucleic acid sequences by multiplex ligation-dependent probe amplification. Nuc Acid Res 30:e57. https://doi. org/10.1093/nar/gnfo56

31. Cotney J, Leng J, Yin J, Reilly SK, DeMare LE, Emera D, Ayoub AE, Rakic P, Noonan JP (2013) The evolution of lineage-specific regulatory activities in the human embryonic limb. Cell 154(1):185-196. https://doi.org/10. 1016/j.cell.2013.05.056
32. Redon R, Ishikawa S, Fitch KR, Feuk L, Perry GH, Andrews TD, Fiegler $H$, Shapero MH, Carson AR, Chen W, Cho EK, Dallaire S, Freeman JL, González JR, Gratacòs M, Huang J, Kalaitzopoulos D, Komura D, MacDonald JR, Marshall CR, Mei R, Montgomery L, Nishimura K, Okamura K, Shen F, Somerville MJ, Tchinda J, Valsesia A, Woodwark C, Yang F, Zhang J, Zerjal T, Zhang J, Armengol L, Conrad DF, Estivill X, Tyler-Smith C, Carter NP, Aburatani H, Lee C, Jones KW, Scherer SW, Hurles ME (2006) Global variation in copy number in the human genome. Nature 444:444-454. https://doi. org/10.1038/nature05329

33. Caonrad DF, Pinto D, Redon R, Feuk L, Gokcumen O, Zhang Y, Aerts J, Andrews TD, Barnes C, Campbell P, Fitzgerald T, Hu M, Ihm CH, Kristiansson K, MacArthur DG, MacDonald JR, Onyiah I, Pang AWC, Robson S, Stirrups K, Valsesia A, Walter K, Wei J, The Wellcome Trust Case Control Consortium, Tyler-Smith C, Carter NP, Lee C, Scherer SW, Hurles ME (2009) Origins and functional impact of copy number variation in the human genome. Nature 464:704-712. https://doi.org/10.1038/nature08516

34. Montalbano A, Juergensen L, Roeth R, Weiss B, Fukami M, Fricke-Otto S, Binder G, Ogata T, Decker E, Nuernberg G, Hassel D, Rappold GA (2016) Retinoic acid catabolizing enzyme CYP26C1 is a genetic modifier in SHOX deficiency. EMBO Mol Med 8(12):1455-1469. https://doi.org/10.15252/ emmm.201606623

35. Li Q, Barkess G, Qian H (2006) Chromatin looping and the probability of transcription. Trends Genet 22:197-202. https://doi.org/10.1016/j.tig. 2006.02.004

36. Kleinjan D-J, Coutinho P (2009) Cis-ruption mechanisms: disruption of cis-regulatory control as a cause of human genetic disease. Brief Funct Genom Proteom 8:317-332. https://doi.org/10.1093/bfgp/elp022

37. Rao SSP, Huntley MH, Durand NC, Stamenova EK, Bochkov ID, Robinson JT, Sanborn AL, Machol I, Omer AD, Lander ES, Lieberman Aiden E (2014) A 3D map of the human genome at kilobase resolution reveals principles of chromatin looping. Cell 159(7):1665-1680. https://doi.org/10.1016/j. cell.2014.11.021

38. Dixon JR, Jung I, Selvaraj S, Shen Y, Antosiewicz-Bourget JE, Young Lee A, Ye Z, Kim A, Rajagopal N, Xie W, Diao Y, Liang J, Zhao H, Lobanenkov W, Ecker JR, Thomson JA, Ren B (2015) Chromatin architecture reorganization during stem cell differentiation. Nature 518:331-336. https://doi.org/ 10.1038 /nature 14222

39. Richardson M, Chong H, Mu W, Conner BR, Hsuan V, Willett S, Lam S, Tsai P, Pesaran T, Chamberlin AC, Park M-S, Gray P, Karam R, Elliott A (2018) DNA breakpoint assay reveals a majority of gross duplications occur in tandem reducing VUS classifications in breast cancer predisposition genes. Genet Med 21:683-693. https://doi.org/10.1038/s41436-018-0092-7

40. Lupiáñez DG, Kraft K, Heinrich V, Krawitz P, Brancati F, Klopocki E, Horn D, Kayserili H, Opitz JM, Laxova R, Santos-Simarro F, Gilbert-Dussardier B, Wittler L, Borschiwer M, Haas SA, Osterwalder M, Franke M, Timmermann B, Hecht J, Spielmann M, Visel A, Mundlos S (2015) Disruptions of topological chromatin domains cause pathogenic rewiring of gene-enhancer interactions. Cell 161(5):1012-1025. https://doi.org/10.1016/j.cell.2015.04. 004

41. Dixon JR, Selvaraj S, Yue F, Kim A, Li Y, Shen Y, Hu M, Liu JS, Ren B (2012) Topological domains in mammalian genomes identified by analysis of chromatin interactions. Nature 485:376-380. https://doi.org/10.1038/ nature11082

\section{Publisher's Note}

Springer Nature remains neutral with regard to jurisdictional claims in published maps and institutional affiliations. 